\title{
Current Medical Treatment of Patients with Non-Colorectal Liver Metastases: Primary Tumor Breast Cancer
}

\author{
Cornelia Liedtke $^{\mathrm{a}}$ Hans-Christian Kolberg $^{\mathrm{b}}$

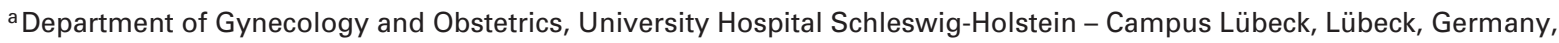 \\ ${ }^{b}$ Department of Gynecology and Obstetrics, Marienhospital Bottrop, Bottrop, Germany
}

Keywords

Metastatic breast cancer - Chemotherapy - Targeted therapy · Endocrine therapy · Signal transduction

\section{Summary}

Background: (Metastatic) breast cancer is a heterogeneous entity in which every disease subtype requires an individualized systemic treatment approach. Methods: We reviewed the currently available data regarding systemic therapy of breast cancer and present a review of historical and current treatment approaches, with the publications cited covering a time span from 1896 to the last ASCO 2015. Results: Systemic therapy of metastatic breast cancer may include chemotherapy, endocrine therapy, and targeted therapies (e.g. antibody-based approaches). Based on the patient's breast cancer subtype, these agents may be employed alone or in combination. Therefore, characterization of the phenotype of the disease is necessary and may include biopsy of the metastatic site. Novel therapeutic approaches include immunologic therapies as well as PARP, PI3K and CDK 4/6 inhibitors, which are currently under investigation in clinical trials. Conclusion: Systemic therapy of metastatic breast cancer requires complex and individualized treatment approaches that are best offered in an interdisciplinary setting.

(c) 2015 S. Karger GmbH, Freiburg

\section{Introduction: Breast Cancer - a Heterogeneous Entity}

Rather than being a homogeneous entity, breast cancer is increasingly recognized to consist of several molecular subtypes that differ significantly with regard to both tumor biology and clinical behavior.

Currently, three different subtypes are relevant:

- Luminal breast cancer: This subtype is HR(hormone receptor)positive; however, significant differences with regard to response to endocrine therapy may be observed. Whereas luminal A breast cancer is commonly highly endocrine sensitive and slowly proliferating, luminal B breast cancer is less endocrine sensitive and comes with a higher proliferation rate which results in a less favorable prognosis.

- HER2-positive breast cancer: This subtype is characterized by an overexpression/amplification of HER2/neu which results in an increased chance of response against HER2-targeted agents such as trastuzumab, pertuzumab, and lapatinib. However, it is increasingly recognized that HER2-positive/HR-positive breast cancer and HER2-positive/HR-negative breast cancer are significantly biologically different.

- Triple-negative breast cancer (TNBC): This subtype is defined by a lack of HR expression (i.e. expression of estrogen receptor (ER) and progesterone receptor (PR)) as well as a lack of overexpression/amplification of the HER2/neu oncogene. Consequently, endocrine treatment and HER2-targeted agents are not indicated and chemotherapy remains the most important agent of choice in all disease settings. Overall, this breast cancer subtype has an unfavorable prognosis with high rates of recurrence and rapid progression in advanced disease stages. The prognosis of patients with TNBC, however, is highly dependent on their response against chemotherapy: If patients respond well to chemotherapy, prognosis may be very favorable [1]. 


\section{Breast Cancer Subtyping in the Metastatic Setting}

It is well known that both HR expression and HER2/neu status may vary during the development of metastatic disease. Pooled relative discordance rates between primary tumors and metastatic disease for ER, PR, and HER2 status of 20\% (95\% confidence interval (CI) $16-35 \%$ ), 33\% (95\% CI 29-38\%), and 8\% (95\% CI 6-10\%), respectively, have been reported [2]. Discordance in receptor expression status may be a result of many biological and technical phenomena. Some of these phenomena constitute of:

- tumor heterogeneity;

- change in receptor status as a result of (targeted) treatment;

- technical issues (fixation schedules, decalcification protocols);

- tumor microenvironment.

Since it is highly important that the molecular subtype of the metastatic entity is well identified, examiners are encouraged to biopsy the metastatic site whenever possible in order to immunohistochemically stain the tumor tissue and to determine the receptor status of the metastasis.

To date, however, there are several open questions with regard to molecular subtyping of metastatic breast cancer:

(1) Breast cancer (and metastatic breast cancer in particular) is known to be highly heterogeneous. Therefore, metastatic sites in a given patient may very well represent distinct molecular entities and thus respond differentially to a given therapy. As a result, the optimal number of biopsies is not defined and may very well not be achieved in a clinical setting.

(2) There is no evidence-based recommendation yet as to how to react to a 'loss' of a given therapeutic target (such as loss of HR or HER2/neu overexpression) - particularly if endocrine therapy is considered as a maintenance option after induction chemotherapy.

\section{Endocrine Therapy}

In hormone-sensitive metastatic breast cancer, endocrine therapy is the therapy of choice [3]. Only in cases of an acutely lifethreatening disease progression chemotherapy should be chosen in ER-positive HER2-negative disease. In contrast, if no such indication exists, endocrine therapy should be preferred. The agents used in endocrine therapy are described in the following paragraphs, with the data cited covering a time span from the first publication on the efficacy of an oophorectomy in 1896 to the latest data presented at the American Society of Clinical Oncology (ASCO) meeting 2015.

\section{Selective Estrogen Receptor Modulators}

In the early 1970s, the first data about the efficacy of tamoxifen, a selective ER modulator, in metastatic breast cancer were published $[4,5]$. With response rates between 16 and 56\% and a superior toxicity profile compared to the former standard, i.e. highdose estrogen [6], tamoxifen was established as the therapy of choice for metastatic breast cancer [7-12]. Although the median time to progression (TTP) with tamoxifen is only about 6 months, the response is robust with patients responding for 12-18 months, in rare cases even years. However, a comparison between tamoxifen and the former standard, diethylstilbestrol - a high-dose estrogen therapy -, showed an inferiority of tamoxifen concerning overall survival (OS) [13]. The main reason for establishing tamoxifen as the new standard over 40 years ago was its superior toxicity profile. Tamoxifen still is a valid option in endocrine therapy of metastatic breast cancer but has become an agent for higher lines of therapy over the years.

\section{Aromatase Inhibitors}

Aromatase inhibitors have replaced tamoxifen in the first line of endocrine therapy for metastatic breast cancer. Unlike tamoxifen, their mechanism of action is not aiming at the ER on the surface of the tumor cell directly, but is suppressing the production of estrogen in the periphery in postmenopausal women. Their response rates and TTP are superior to tamoxifen whereas their toxicity profile is comparable [14].

The first studies on aromatase inhibitors compared them in the second line after tamoxifen therapy to the former second-line standard megestrol or medroxyprogesterone acetate $[15,16]$. In several studies, a significant benefit for OS could be shown for anastrozole $[17,18]$, as well as a significantly longer time to treatment failure and a significantly higher response rate for letrozole [19]. The only steroidal aromatase inhibitor (exemestane) proved to provide a significant benefit concerning TTP, time to treatment failure, and OS [20,21]. The toxicity profiles of all three aromatase inhibitors were superior compared to megestrol or medroxyprogesterone.

In the first-line setting, aromatase inhibitors were superior compared to tamoxifen. Whereas the results concerning anastrozole were contradictory - in one study no significant superiority to tamoxifen could be seen [22], while another investigation published at the same time showed a better progression-free survival (PFS) and clinical benefit rate [23] -, letrozole and exemestane proved to have a significantly better effect on response rate, clinical benefit rate, and PFS [24-26].

These data led to the establishment of aromatase inhibitors as a first-line standard. Although there are competitors on the horizon, aromatase inhibitors still represent a mainstay in the endocrine therapy of metastatic breast cancer in postmenopausal women.

\section{Selective Estrogen Receptor Downregulators}

Another option in the endocrine treatment of metastatic breast cancer is the selective ER downregulator fulvestrant. Unlike tamoxifen, it is completely lacking the partial estrogen agonism that may be a reason for treatment failures and definitely is the reason for the elevated risk for endometrial cancer in postmenopausal women treated with tamoxifen [27]. A direct comparison with anastrozole in higher lines of therapy resulted in a proof of noninferiority [28], whereas the comparison with tamoxifen in the first line showed no superiority of fulvestrant. In the overall population of this study, which included patients with unknown receptor sta- 
tus, fulvestrant even showed a trend for inferiority; however, in the patients with proven hormone sensitivity no differences were seen [14]. Further investigations on fulvestrant focused on the dosage and resulted in a change of the standard dose from 250 to $500 \mathrm{mg}$ [29]. This finally led to a proof of superiority for anastrozole in the first-line setting in a phase II study [30]. The ongoing phase III trial FALCON, comparing fulvestrant and anastrozole in the first line, will hopefully answer the question of where fulvestrant will find its place in the endocrine treatment cascade of metastatic breast cancer.

\section{Luteinizing Hormone Agonists}

For many years the endocrine therapy of choice for premenopausal women suffering from metastatic breast cancer was oophorectomy $[8,31]$. Since the development of tamoxifen researchers have tried to establish an alternative to surgery by comparing the drug with the operation in premenopausal patients, thus trying to spare patients the risks of surgery and the psychological trauma of the oophorectomy [32]. Although tamoxifen seems to have a comparable effect as ovarian suppression, the published results failed to prove equal efficacy, mainly for methodological reasons $[9,33]$. One of the main caveats of tamoxifen in premenopausal patients with intact ovaries is its ability to cause high peaks of estrogen levels with unknown - possibly damaging - effects on the course of the disease. The development of luteinizing hormone agonists as agents leading to an ovarian suppression offered a way out of this dilemma. Whereas the first use of the new agents was mainly led by the idea of replacing surgery [34], the strategy of combining ovarian suppression with tamoxifen was the next and logical step. This was based on the idea of ovarian suppression leading to an artificial menopause, thus making it possible to apply the known benefits of tamoxifen for postmenopausal patients to the premenopausal setting. A large meta-analysis showed significant benefits for response rates, progression-free interval, and OS [35] for the combination of luteinizing hormone agonists and tamoxifen and implemented this therapy as the standard for premenopausal patients.

\section{Chemotherapy and Targeted Agents for Metastatic Breast Cancer}

\section{Indication for Chemotherapy in Metastatic Breast Cancer}

Overall, an indication for chemotherapy in metastatic breast cancer may be seen in three situations:

- HR-positive/HER2-negative breast cancer unsuitable for endocrine intervention alone due to (i) resistance to endocrine interventions or (ii) rapid (life-threatening) disease progression and high need for remission;

- TNBC as there are yet no relevant targets suitable for targeted therapy outside of clinical trials;

- HER2-positive metastatic breast cancer (because chemotherapy is part of the majority of several HER2-targeted treatment regimens).

\section{Monochemotherapy versus Polychemotherapy}

If chemotherapy is indicated, monotherapy is usually applied. Although polychemotherapy has been shown to increase response rates and even prolong PFS rates compared to monochemotherapy, this may be counterbalanced by an increased rate of (severe) toxicities. Therefore, combination chemotherapy in metastatic breast cancer (i.e. combination of taxanes with either anthracyclines or antimetabolites) should be restricted to cases with severe symptoms and high need for remission.

Choice of Agents

In some cases (such as in HER2-targeted therapy), certain chemotherapy agents (such as docetaxel with pertuzumab/trastuzumab or capecitabine with lapatinib) may be selected based upon licensing issues or as an evidence-based approach focusing on efficacy in certain combination regimens. In other cases, the selection of chemotherapy agents is less strict. Since taxanes and anthracyclines are considered to represent the most efficacious agents in breast cancer chemotherapy, these agents should be used before other agents are selected unless (i) there are contraindications or (ii) these agents have already been used in earlier disease stages.

Overall, factors that assist in choosing the optimal combination chemotherapy agent are:

- ER/PR, HER2; combination with biologicals;

- previous treatments (and their toxicities);

- recurrence-free interval following adjuvant therapy;

- aggressiveness of disease, localization of metastases;

- estimated survival time;

- concurrent diseases (including organ function);

- expectations/preference of patient [36].

Agents that may be used are:

- Taxanes (paclitaxel/docetaxel/nab-paclitaxel);

- anthracyclines (epirubicin/doxorubicin/(PEG-)liposomal doxorubicin);

- platinum (carboplatin/cisplatin);

- vinorelbine;

- capecitabine;

- eribulin;

- gemcitabine.

Although the optimal duration of chemotherapy is still and repeatedly a matter of debate, there is consensus that the duration of a given chemotherapy regimen should be restricted to the patient's therapeutic index (i.e. therapeutic efficacy vs. therapeutic toxicity) remaining positive [37].

There is yet limited evidence as to whether certain breast cancer molecular subtypes derive a particular benefit from specific chemotherapy agents, and evidence is even more limited in metastatic disease. However, there is accumulating evidence which supports a particular role for platinum salts among patients with hereditary breast cancer (i.e. those harboring a BRCA mutation). For a long time, evidence was limited to data from retrospective analyses. However, this has changed since the publication of the results from the British TNT (Triple Negative Trial) study. In this study, patients with either TNBC or metastatic breast cancer with a muta- 
tion in BRCA1 or BRCA 2 were randomized to either taxane monotherapy (docetaxel $100 \mathrm{mg} / \mathrm{m}^{2} \mathrm{q} 3 \mathrm{w}, 6$ cycles) or carboplatin (AUC6, q3w, 6 cycles) [38]. Analysis of the primary study endpoint (response rate following 3-6 cycles) showed a significant difference in favor of the therapy with platinum salts among patients with hereditary breast cancer (response rates for carboplatin vs. docetaxel 68 vs. $33 \%$, respectively; $p=0.03$ ). For patients with metastatic non-hereditary breast cancer no significant association was observed ( 28 vs. $37 \%, \mathrm{p}=0.16$ ). Therefore, the German Gynecological Oncology Group (Arbeitsgemeinschaft Gynäkologische Onkologie (AGO)) has recommended the preference of platinum salts (i.e. carboplatin) to taxanes (i.e. docetaxel) among patients with metastatic breast cancer carrying a BRCA1 or BRCA2 mutation.

\section{Use of Antiangiogenic Therapy}

The most prominent antiangiogenic agent in oncology is bevacizumab, which represents a humanized monoclonal immunoglobulin $\mathrm{G}$ antibody against the vascular endothelial growth factor. In Germany, bevacizumab is licensed for use in patients with HER2negative metastatic breast cancer as part of first-line therapy in combination with either paclitaxel or capecitabine. Of note, in a direct comparison of both treatment regimens, the paclitaxel combination seems to be slightly more efficacious compared to bevacizumab/capecitabine (TURANDOT trial, median PFS 11.0 vs. 8.1 months) [39].

The use of bevacizumab in breast cancer, however, is still a matter of debate both in Germany and internationally, given that across all trials the addition of bevacizumab to chemotherapy has improved PFS rates but no OS endpoints: for instance, in the pivotal ECOG 2100 study which led to the approval of bevacizumab, median PFS was 11.8 vs. 5.9 months for the first-line use of paclitaxel with and without bevacizumab, respectively [40]. Similar rates have been shown for capecitabine (RIBBON-1, 8.6 vs. 5.7 months) [41]. In contrast, even in meta-analyses of these trials, the hazard ratio (HR) for OS in association with the use of bevacizumab was 0.95 (95\% CI: 0.85-1.06) [42]. In fact, the efficacy data regarding bevacizumab has triggered an intense debate as to which efficacy endpoint has the most value among patients with metastatic breast cancer.

Nevertheless, bevacizumab is not only licensed in both combinations in first-line therapy but is also recommended for use in this setting as part of German national treatment recommendations [43].

\section{Chemotherapy with HER2-Targeted Agents}

For a long time, the prognosis of patients with HER2-positive breast cancer was considered to be the most unfavorable among all subtypes of breast cancer. The development of the monoclonal HER2-targeted antibody trastuzumab, however, has changed this perception dramatically [44]. HER2-positive disease, despite usually representing a fast proliferating, highly aggressive entity, is currently regarded to represent one of the subtypes with the largest number of highly efficacious treatment options. Therefore, rather than being an unfavorable prognostic factor, HER2 is nowadays re- garded as a favorable predictive parameter since it represents the prerequisite for an increasing number of highly active HER2-targeted agents.

\section{HER2-Targeted Antibodies and Antibody-Drug Conjugates}

The first antibody that was developed against the HER2/neu receptor is the monoclonal antibody trastuzumab. Trastuzumab is a humanized monoclonal antibody targeted against the extracellular domain of the HER2 receptor. Due to the use of trastuzumab in combination with monochemotherapy, significant improvements in OS have been demonstrated [45]. Nowadays, trastuzumab is regarded as the first agent in the era of molecularly targeted agents in breast cancer and thus as a forerunner to a paradigm shift in the treatment of the disease.

Recently, the development of another HER2-targeted monoclonal antibody has improved the efficacy of trastuzumab even further. Pertuzumab is a monoclonal antibody directed against the HER2/HER3 dimerization domain of the HER2 receptor. If patients are treated with trastuzumab and pertuzumab in combination with docetaxel as part of a first-line chemotherapy regimen, OS rates of as high as 56.5 months may be reached [46]. Therefore, this regimen is considered as today's first-line chemotherapy standard regimen for patients with HER2-positive metastatic breast cancer.

Antibody-drug conjugates (ADC) offer another treatment option for patients with HER2-positive breast cancer. Trastuzumab-emtansine (TDM-1) is a highly effective antibody-drug conjugate of the cytotoxic DM1 and trastuzumab. After internalization of the ADC the cytotoxin is released and targets the tumor cell from the inside. The use of TDM-1 may also increase both PFS and OS rates. In the pivotal EMILIA study, which eventually served as a registration study for TDM-1 in metastatic HER2-positive breast cancer, OS rates for TDM-1 compared to capecitabine/lapatinib were 30.9 vs. 25.1 months [47]. TDM-1 is licensed for use in patients with HER2positive metastatic breast cancer either as part of a second-line treatment regimen or in case of fast progression ( $<6$ months) after a trastuzumab-based treatment regimen in the curative setting.

\section{Small Molecules Targeting HER2 Signaling}

Apart from HER2-directed antibodies, HER2 signaling may also be abrogated by the use of small molecules. Lapatinib was the second HER2-targeted agent which was registered for HER2-positive metastatic breast cancer in combination with capecitabine, and is a small molecule targeting both HER1/EGFR and HER2. Registration was based upon the results of a randomized study showing a PFS benefit of approximately 4 months for the combination of capecitabine/lapatinib versus capecitabine alone (HR 0.34, p < 0.001) [48]. However, since both pertuzumab/trastuzumab and TDM1 have demonstrated an OS benefit, lapatinib is largely recognized as a treatment option for later-line therapy. In addition to lapatinib/capecitabine, lapatinib is also registered for the treatment of HER2-positive/HR-positive breast cancer in combination with letrozole [49] as well as for patients with HER2-positive/HR-negative breast cancer in combination with trastuzumab [50]. 


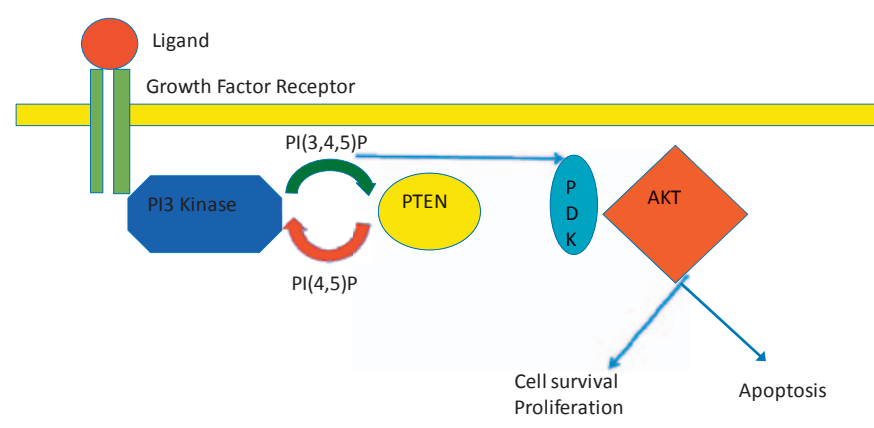

Fig. 1. PI3K pathway.

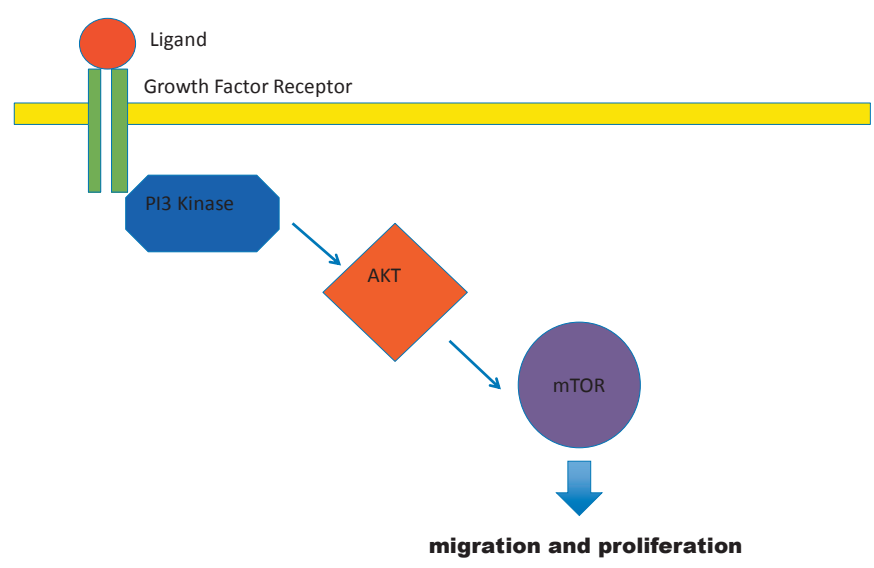

Fig. 2. mTOR pathway.

Neratinib is a novel member of the family of HER2-targeted agents. The small molecule irreversibly targets HER1, HER2, and HER4 and has not been licensed yet for the treatment of breast cancer. The agent, however, demonstrated significant efficacy in an adjuvant study presented at the recent meeting 2015 [51] and is currently under investigation in several trials, including a head-tohead combination of capecitabine and neratinib versus capecitabine and lapatinib (NALA, NCT01808573).

\section{Novel Agents for the Treatment of Metastatic Breast Cancer}

\section{PI3K/mTOR Inhibitors in Hormone Receptor-Positive Breast Cancer}

The phosphoinositide 3-kinase (PI3K)/activated protein kinase $(\mathrm{AKT}) /$ mammalian target of rapamycin (mTOR) (fig. 1, 2) pathway plays an important role in cell growth, survival and proliferation. It is also a central part of signal transduction for cell metabolism [52]. The pathway is activated by growth factors, leading to a phosphorylation of PI3K. One of the inhibitors of the PI3K/AKT/ mTOR pathway is phosphatase and tensin homolog (PTEN), a tumor suppressor gene that inhibits the activation of AKT. As in many other tumors, this pathway is activated in breast cancer. This happens either because of mutations in PTEN, PIK3CA, or AKT or because of amplifications or mutations of receptor tyrosine kinases such as HER2. Since there is an intensive crosstalk between the signaling of the estrogen receptor and PI3K, the PI3K/AKT/mTOR pathway is considered to play a major role in the development of endocrine resistance [53]. In the last years, several targeted therapies inhibiting the pathway have been developed in order to find a way to overcome endocrine resistance in combination with fulvestrant or aromatase inhibitors. Table 1 summarizes the results of the most important studies on PI3K and mTOR inhibition in hormone-sensitive metastatic breast cancer. Whereas the development of therapies targeting PI3K is still in the stage of clinical studies, the combination of the mTOR inhibitor everolimus with the steroidal aromatase inhibitor exemestane is already a standard therapy after the failure of a non-steroidal aromatase inhibitor such as anastrozole or letrozole. If the patient has not received a non-steroidal aromatase inhibitor in the adjuvant setting, the therapy with everolimus and exemestane is used in second or higher lines, whereas patients who have been treated with anastrozole or letrozole during the course of the adjuvant therapy may receive the combination of an mTOR inhibitor and a steroidal aromatase inhibitor as a firstline therapy option at the time of generalization of the disease.

\section{PI3K/mTOR Inhibitors in HER2-Positive Breast Cancer}

There is an increasingly solid body of evidence that alterations of the PI3K/AKT/mTOR pathway in addition to mediating endocrine resistance may also be involved in mediating resistance against HER2-targeted agents in HER2-positive breast cancer. Several analyses including one meta-analysis demonstrate that alterations in PI3K signaling, such as alterations of PIK3CA, may confer resistance against dual blockade with trastuzumab and lapatinib (i.e. decrease rates of pathological remission in neoadjuvant therapy regimens) and may even be associated with adverse survival, particularly in HER2-positive/HR-positive subtypes [54].

The BOLERO- 1 and BOLERO- 3 studies evaluated mTOR inhibition by means of everolimus in HER2-positive breast cancer in combination with trastuzumab among patients with HER2-positive metastatic breast cancer. In a translational analysis using patient samples from these studies, Slamon et al. [55] evaluated whether there was an association between alteration in the PI3K/ mTOR cascade and efficacy of everolimus in reversing trastuzumab resistance. In fact, PI3K mutations as well as other PI3K pathway alterations led to an increased everolimus efficacy [55].

These analyses demonstrate that PI3K targeting may hold the promise of not only reversing endocrine resistance (i.e. through the use of everolimus in combination with exemestane) but also of reversing resistance against HER2-targeted agents in certain HER2positive subtypes. The latter indication, however, needs to be studied more intensely before its translation into clinical practice outside of clinical trials.

\section{CDK 4/6 Inhibitors}

Dysregulation of the cell cycle is a major characteristic of cancer. The family of cycline-dependent kinases (CDK) is an important factor in the regulation of the cell cycle. CDK 4 and 6 as well as 
Table 1. Results for the use of mTOR and PI3K inhibitors in hormone-sensitive metastatic breast cancer (modified from [64])

\begin{tabular}{|c|c|c|c|c|c|}
\hline Substance & Inhibition & Phase & $\mathrm{N}$ & Combination partners & Clinical benefit \\
\hline Everolimus (BOLERO-2) & mTOR & III & 724 & exemestane & PFS: 10.6 vs. 4.1 months [65] \\
\hline Tamoxifen (TAMRAD) & mTOR & II & 111 & tamoxifen & TTP: 8.6 vs. 4.5 months [66] \\
\hline Ridaforolimus & mTOR & II / random. & 80 & $\begin{array}{l}\text { dalotuzumab / } \\
\text { exemestane }\end{array}$ & $\begin{array}{l}\text { PFS not significant }{ }^{\mathrm{a}} \\
\text { HR 1.18; 80\%-CI: } 0.8-1.72 ;(\mathrm{p}=0.565) \text { [67] }\end{array}$ \\
\hline BKM120 (Burparlisib) & $\begin{array}{l}\text { PI3K } \\
\text { class I (pan) }\end{array}$ & $\mathrm{Ib}$ & 51 & letrozole & clinical benefit rate: $31 \%[68]$ \\
\hline BKM120 (Burparlisib) & $\begin{array}{l}\text { PI3K } \\
\text { class I (pan) }\end{array}$ & I & 31 & fulvestrant & evidence for antitumor activity [69] \\
\hline $\begin{array}{l}\text { GDC } 0941 \text { (Pictilisip) / } \\
\text { FERGI trial }\end{array}$ & $\begin{array}{l}\text { PI3K } \\
\text { class I (pan) }\end{array}$ & II / random. & 168 & fulvestrant & $\begin{array}{l}\text { PFS: } 6.6 \text { vs. } 5.1 \text { months }[70]^{\mathrm{b}} \\
\text { more benefit for ER-/PR-positive tumors }\end{array}$ \\
\hline BYL719 & $\begin{array}{l}\text { PI3K } \\
\text { selective } \\
\text { (class } 1, \alpha)\end{array}$ & I & 64 & $\begin{array}{l}\text { fulvestrant stratified } \\
\text { for PI3K mutations }\end{array}$ & evidence for antitumor activity $[71]^{c}$ \\
\hline BYL719 & $\begin{array}{l}\text { PI3K } \\
\text { selective } \\
\text { (class } 1, \alpha)\end{array}$ & I & 14 & letrozol or exemestane & evidence for antitumor activity [72] \\
\hline
\end{tabular}

a23.3 weeks (with ridaforolimus) vs. 31.9 weeks.

bNot statistically significant; PIK3CA mutations were not predictive for response.

${ }^{c}$ Partial remissions were only seen in patients with PIK3CA mutations.

$\mathrm{PFS}=$ Progression-free survival; TTP = time to progression; HR = hazard ratio; ER = estrogen receptor; $\mathrm{PR}=$ progesterone receptor.

cycline $\mathrm{D}$ are responsible for the transition from $\mathrm{G} 1$ phase to $\mathrm{S}$ phase through phosphorylation of retinoblastoma and thus are crucial for the cell cycle (fig. 3) [56]. Three agents serving as inhibitors of CDK 4/6 activity are currently undergoing intensive development in metastatic breast cancer: palbociclib, ribociclib (LEE011), and abemaciclib. Palbociclib is the agent immediately awaiting approval. In 2009, the inhibitory effect of palbociclib on ER-positive breast cancer cells was demonstrated in vitro [57]. This fueled the further development of the substance in the setting of advanced ER-positive breast cancer. A phase II study (PALOMA-1) comparing letrozole plus palbociclib in the first-line therapy for metastatic or advanced disease resulted in a prolongation of the PFS from 10.2 to 20.2 months and led to an accelerated approval of palbociclib in combination with letrozole as first-line endocrine therapy by the Food and Drug Administration (FDA). A phase III trial (PALOMA-2) has recently completed accrual [58]. For patients after failure of endocrine therapy, data from a phase III trial are already available (PALOMA-3): Here, the investigators chose fulvestrant as an endocrine combination partner for palbociclib and as the competitor in the control arm. In the combination arm, patients had a median PFS of 9.2 months, which proved to be significantly superior to the 3.8 months in the control arm [59]. After these promising results and the approval by the FDA, final approval in Europe is awaited for the end of 2015, probably at first for first-line therapy in combination with letrozole.

The available data for abemaciclib and ribociclib (LEE011) also show clinical efficacy and no unexpected warning signs $[60,61]$. Table 2 presents the current study portfolio for CDK $4 / 6$ inhibition in metastatic breast cancer.
Fig. 3. $C D K 4 / 6$ and cell cycle. $\mathrm{M}=$ Mitosis; $\mathrm{pRb}=$ phosphorylated retinoblastoma; $\mathrm{S}=$ DNA replication; $\mathrm{G} 1=$ growth; $\mathrm{G} 2$ = growth 2 .

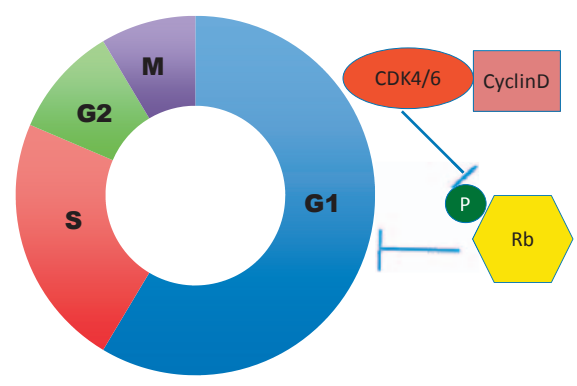

The CDK 4/6 inhibitors are one of the most promising innovations in the management of breast cancer in the past few years and are expected to change the course of endocrine therapy.

\section{Immune Oncology}

Numerous analyses have shown that tumor cell-immune cell interaction plays an important role in breast cancer in general and in triple-negative disease in particular. For instance, translational analyses of patients with TNBC show that these patients derive an increased benefit from neoadjuvant chemotherapy if their tumor presents with a strong lymphocytic infiltrate.

Consequently, immunologicals are currently under intensive investigation in several malignant entities including breast cancer. These agents act through an alteration of the tumor cell-immune system interaction, which eventually leads to a demasking of the tumor cell and allows for the immune system to recognize and attack the tumor cell. The efficacy of these types of agents does therefore strongly depend on the mutational frequency of the tumor type. The most promising results yet have been published in the 
Table 2. Active studies with CDK $4 / 6$ inhibitors in metastatic breast cancer

\begin{tabular}{|c|c|c|c|}
\hline Agent & Phase & Regimen & Patients (planned enrollment, $\mathrm{N}$ ) \\
\hline $\begin{array}{l}\text { Palbociclib } \\
\text { (PD0332991) }\end{array}$ & $\begin{array}{l}\text { phase } 3 \text { (PALOMA-2) } \\
\text { (NCT01740427); } \\
\text { phase } 2 \\
\text { (INGE-B) } \\
\text { (Eudract 2015-001603-32) }\end{array}$ & $\begin{array}{l}\text { palbociclib + LET vs. } \\
\text { LET + PBO } \\
\text { palbociclib + LET vs. } \\
\text { letrozole }\end{array}$ & $\begin{array}{l}\text { ER+, HER2- MBC (450) } \\
\text { ER+, HER2- MBC without previous } \\
\text { endocrine treatment for MBC (120) }\end{array}$ \\
\hline LEE011 & $\begin{array}{l}\text { phase } 3 \text { (MONALEESA-2) } \\
\text { (NCT01958021); } \\
\text { phase } 1 / 2 \\
\text { (NCT01857193); } \\
\text { phase } 1 / 2 \\
\text { (NCT01872260) }\end{array}$ & $\begin{array}{l}\text { LEE011 + LET vs. } \\
\text { LET + PBO } \\
\text { LEE011 + EVE + } \\
\text { EXE } \\
\text { LEE011 + BYL719 + } \\
\text { LET }\end{array}$ & $\begin{array}{l}\text { ER+, HER2- MBC without previous } \\
\text { treatment for MBC (500) } \\
\text { ER+, HER2- MBC or LABC resistant } \\
\text { towards LET or ANA (185) } \\
\text { ER+ MBC or LABC (130) }\end{array}$ \\
\hline $\begin{array}{l}\text { Abemaciclib } \\
\text { (LY2835219) }\end{array}$ & $\begin{array}{l}\text { phase } 3 \text { (MONARCH-2) } \\
\text { NCT02107703 }\end{array}$ & $\begin{array}{l}\text { abemaciclib + FUL } \\
\text { vs. FUL }\end{array}$ & $\begin{array}{l}\text { ER+, HER2- MBC (no previous endocrine } \\
\text { therapy or progression on previous therapy } \\
\text { with AI or TAM) (550) }\end{array}$ \\
\hline
\end{tabular}

$\mathrm{MBC}=$ Metastatic breast cancer; $\mathrm{LET}=$ letrozole; $\mathrm{PBO}=$ placebo; $\mathrm{FUL}=$ fulvestrant; $\mathrm{ANA}=$ anastrozole; $\mathrm{EVE}=$ everolimus; $\mathrm{AI}=$ aromatase inhibitor; $\mathrm{TAM}=$ tamoxifen $\mathrm{EXE}=$ exemestane; $\mathrm{LABC}=$ locally advanced breast cancer. context of malignant melanoma. However, both the high mutational frequency and the need to develop novel therapeutic concepts other than chemotherapy have fostered the development of immune oncology also in the TNBC subtype. Of particular interest as a target in TNBC is the programmed cell death protein 1 (PD-1) and its two ligands PD-L1 and PD-L2. All three proteins may be inactivated by the use of humanized antibodies in order to inactivate their interaction. At the San Antonio Breast Cancer Symposium (SABCS) 2014, results of a phase I clinical trial were presented which analyzed the efficacy and safety of pembrolizumab (Keytruda) among patients with TNBC. Among 27 patients, one case of complete remission, four cases of partial remission, and seven cases of stable disease were assessed. No significant safety signals were recorded [62].

\section{PARP Inhibition}

The enzyme poly(ADP-ribose) polymerase (PARP) is involved in a large number of intracellular processes. One of the most significant functions is the repair of DNA damage. Inhibition of PARP in tumor cells may inhibit their capacity to repair DNA damage resulting from both radiation and cytotoxic therapy [63]. This aspect is of particular interest in patients with (triple-negative) breast cancer harboring a BRCA mutation, since these tumors already suffer from an impaired DNA damage capacity.

The mechanism of action of PARP inhibitor is often referred to as synthetic lethality, which describes a combined effect of i) inhibition of BRCA function through a genetic/somatic mutation and ii) iatrogenic inhibition of the compensatory role of PARP through application of PARP inhibitors.

Several PARP inhibitors are currently under intensive investigation among all stages of TNBC and/or hereditary (i.e. BRCA-associated) breast cancer.

\section{Disclosure Statement}

The authors have the following potential conflicts of interest with respect to the content of this manuscript to declare: CL has received honoraria from Amgen, Celgene, Eisai, GSK, Novartis, Pierre-Fabre, Roche, and TEVA. HCK has received honoraria from Novartis, GSK, Pfizer, Roche, TEVA, Amgen, Janssen, and LIV Pharma.

\section{References}

$\checkmark 1$ Liedtke C, Mazouni C, Hess KR, André F, Tordai A, Mejia JA, Symmans WF, Gonzalez-Angulo AM, Hennessy B, Green M, Cristofanilli M, Hortobagyi GN, Pusztai L: Response to neoadjuvant therapy and longterm survival in patients with triple-negative breast cancer. J Clin Oncol 2008;26:1275-1281.

2 Amir E, Miller N, Geddie W, Freedman O, Kassam F, Simmons C, Oldfield M, Dranitsaris G, Tomlinson G, Laupacis A, Tannock IF, Clemons M: Prospective study evaluating the impact of tissue confirmation of metastatic disease in patients with breast cancer. J Clin Oncol 2012;30:587-592.
3 www.ago-online.de.

4 Morgan LR Jr, Schein PS, Woolley PV, Hoth D, Macdonald J, Lippman M, Posey LE, Beazley RW: Therapeutic use of tamoxifen in advanced breast cancer: correlation with biochemical parameters. Cancer Treat Rep 1976;60:1437-1443.

5 Rose C, Mouridsen HT: Treatment of advanced breast cancer with tamoxifen. Recent Results Cancer Res 1984; 91:230-242.
6 Peethambaram PP, Ingle JN, Suman VJ, Hartmann LC, Loprinzi CL: Randomized trial of diethylstilbestrol vs. tamoxifen in postmenopausal women with metastatic breast cancer: an updated analysis. Breast Cancer Res Treat 1999;54:117-122.

7 Bratherton DG, Brown CH, Buchanan R, Hall V, Kingsley Pillers EM, Wheeler TK, Williams CJ: A comparison of two doses of tamoxifen (Nolvadex) in postmenopausal women with advanced breast cancer: $10 \mathrm{mg}$ bd versus $20 \mathrm{mg}$ bd. Br J Cancer 1984;50:199-205. 
8 Manni A, Trujillo JE, Marshall JS, Brodkey J, Pearson $\mathrm{OH}$ : Antihormone treatment of stage IV breast cancer. Cancer 1979;43:444-450.

9 Sawka CA, Pritchard KI, Shelley W, DeBoer G, Paterson AH, Meakin JW, Sutherland DJ: A randomized crossover trial of tamoxifen versus ovarian ablation for metastatic breast cancer in premenopausal women: a report of the National Cancer Institute of Canada Clinical Trials Group (NCIC CTG) trial MA.1. Breast Cancer Res Treat 1997;44:211-215.

10 Tormey DC, Simon RM, Lippman ME: Evaluation of tamoxifen dose in advanced breast cancer: a progress report. Cancer Treat Rep 1976;60:1451-1459.

11 Ward HWC: Anti oestrogen therapy for breast cancer: a trial of tamoxifen at two dose levels. Br Med J 1973;1: $13-14$.

12 Westerberg H, Nordenskjold B, de Schryver A, Notter G: Antio-estrogen therapy of advanced mammary carcinoma. Acta Radiol Ther Phys Biol 1976;15:513-518.

13 Ingle JN, Ahmann DL, Green SJ, Edmonson JH, Bisel HF, Kvols LK, Nichols WC, Creagan ET, Hahn RG, Rubin J, Frytak S: Randomized trial of diethylstilbestrol versus tamoxifen in postmenopausal women with advanced breast cancer. N Engl J Med 1981;304:16-21.

14 Howell A, Robertson JFR, Abram P, Lichinitser MR, Elledge R, Bajetta E, Watanabe T, Morris C, Webster A, Dimery I, Osborne CK: Comparison of fulvestrant versus tamoxifen for the treatment of advanced breast cancer in postmenopausal women previously untreated with endocrine therapy: a multinational, doubleblind, randomized trial. J Clin Oncol 2004;22:16051613.

15 Abrams J, Aisner J, Cirrincione C, Berry DA, Muss HB, Cooper MR, Henderson IC, Panasci L, Kirshner J, Ellerton J, Norton L: Dose-response trial of megestrol acetate in advanced breast cancer: cancer and leukemia group B phase III study 8741. J Clin Oncol 1999;17: 64-73.

16 Muss HB, Case LD, Atkins JN, et al: Tamoxifen versus high-dose medroxyprogesterone acetate as initial endocrine therapy for patients with metastatic breast cancer: a Piedmont Oncology Association study. J Clin Oncol 1994;12:1630-1638.

- 17 Buzdar A, Jonat W, Howell A, et al: Anastrozole, a potent and selective aromatase inhibitor, versus megestrol acetate in postmenopausal women with advanced breast cancer: results of overview and analysis of two phase III clinical trials. Arimidex Study Group. J Clin Oncol 1996;14:2000-2011.

18 Jonat W, Howell A, Blomqvist C, Eiermann W, Winblad G, Tyrrell C, Mauriac L, Roche H, Lundgren S, Hellmund R, Azab M: A randomized trial comparing two doses of the new selective aromatase inhibitor anastrozole (Arimidex) with megestrol acetate in postmenopausal patients with advanced breast cancer: The Arimidex Study Group. Eur J Cancer 1996;32A:404412.

19 Dombernowsky P, Smith I, Falkson G, Leonard R, Panasci L, Bellmunt J, Bezwoda W, Gardin G, Gudgeon A, Morgan M, Fornasiero A, Hoffmann W, Michel J, Hatschek T, Tjabbes T, Chaudri HA, Hornberger U, Trunet PF: Letrozole, a new oral aromatase inhibitor for advanced breast cancer: double-blind randomized trial showing a dose effect and improved efficacy and tolerability compared with megestrol acetate. J Clin Oncol 1998;16:453-461.

20 Kaufmann M, Bajetta E, Dirix LY, Fein LE, Jones SE, Zilembo N, Dugardyn JL, Nasurdi C, Mennel RG, Cervek J, Fowst C, Polli A, di Salle E, Arkhipov A, Piscitelli G, Miller LL, Massimini G: Exemestane is superior to megestrol acetate after tamoxifen failure in postmenopausal women with advanced breast cancer: results of a phase III randomized double-blind trial: The Exemestane Study Group. J Clin Oncol 2000;18:1399-1411.
21 Loenning PE, Bajetta E, Murray R, Tubiana-Hulin M, Eisenberg PD, Mickiewicz E, Celio L, Pitt P, Mita M, Aaronson NK, Fowst C, Arkhipov A, di Salle E, Polli A, Massimini G: Activity of exemestane in metastatic breast cancer after failure of nonsteroidal aromatase inhibitors: a phase II trial. J Clin Oncol 2000;18:22342244.

22 Bonneterre J, Thurlimann B, Robertson JF, Krzakowski M, Mauriac L, Koralewski P, Vergote I, Webster A, Steinberg M, von Euler M: Anastrozole versus tamoxifen as first-line therapy for advanced breast cancer in 668 postmenopausal women: results of the Tamoxifen or Arimidex Randomized Group Efficacy and Tolerability study. J Clin Oncol 2000;18:37483757.

23 Nabholtz JM, Buzdar A, Pollak M, Harwin W, Burton G, Mangalik A, Steinberg M, Webster A, von Euler M: Anastrozole is superior to tamoxifen as first-line therapy for advanced breast cancer in postmenopausal women: results of a North American randomized trial. Arimidex Study Group. J Clin Oncol 2000;18:37583767.

24 Mouridsen H, Gershanovich M, Sun Y, et al: Superior efficacy of letrozole versus tamoxifen as first-line therapy for postmenopausal women with advanced breast cancer: results of a phase III study of the International Letrozole Breast Cancer Group. J Clin Oncol 2001;19: 2596-2606.

25 Mouridsen H, Gershanovich M, Sun Y, Perez-Carrion R, Boni C, Monnier A, Apffelstaedt J, Smith R, Sleeboom HP, Jaenicke F, Pluzanska A, Dank M, Becquart D, Bapsy PP, Salminen E, Snyder R, Chaudri-Ross H, Lang R, Wyld P, Bhatnagar A: Phase III study of letrozole versus tamoxifen as first-line therapy of advanced breast cancer in postmenopausal women: analysis of survival and update of efficacy from the International Letrozole Breast Cancer Group. J Clin Oncol 2003;21: 2101-2109.

26 Paridaens R, Therasse P, Dirix L, Beex L, Piccart M, Cameron D, Cufer T, Roozendaal K, Nooij M, Mattiacci MR: First line hormonal treatment (HT) for metastatic breast cancer (MBC) with exemestane (E) or tamoxifen ( $\mathrm{T}$ ) in postmenopausal patients (pts) - a randomized phase III trial of the EORTC Breast Group. Proc ASCO 2004;23:abstr 515.

27 Perey L, Thurlimann B, Hawle H, Bonnefoi H, Aebi S, Pagani O, Goldhirsch A, Dietrich D: Fulvestrant ('Faslodex') as hormonal treatment in postmenopausal women with advanced breast cancer progressing after treatment with tamoxifen and aromatase inhibitors. Breast Cancer Res Treat 2002;76(S72):abstr 249.

28 Howell A, Robertson JF, Quaresma Albano J, Aschermannova A, Mauriac L, Kleeberg UR, Vergote I, Erikstein B, Webster A, Morris C: Fulvestrant, formerly ICI 182,780 , is as effective as anastrozole in postmenopausal women with advanced breast cancer progressing after prior endocrine treatment. J Clin Oncol 2002;20: 3396-3403.

29 Di Leo A, Jerusalem G, Petruzelka L, Torres R, Bondarenko IN, Khasanov R, Verhoeven D, Pedrini JL, Smirnova I, Lichinitser MR, Pendergrass K, Malorni L, Garnett S, Rukazenkov Y, Martin M: Final overall survival: fulvestrant $500 \mathrm{mg}$ vs $250 \mathrm{mg}$ in the randomized CONFIRM trial. J Natl Cancer Inst 2014;106:djt337.

30 Robertson JF, Llombart-Cussac A, Feltl D, Rolski J, Feltl D, Dewar J, Emerson L, Dean A, Ellis MJ: Fulvestrant $500 \mathrm{mg}$ versus anastrozole $1 \mathrm{mg}$ for the first-line treatment of advanced breast cancer: follow-up analysis from the randomized 'FIRST' study. Breast Cancer Res Treat 2012;136:503-511.

31 Beatson AT: On the treatment of inoperable cases of carcinoma mamma: suggestion for a new method of treatment with illustrative cases. Lancet 1896;2:104107.
2 Ingle JN, Krook JE, Green SJ, et al: Randomized trial of bilateral oophorectomy versus tamoxifen in premenopausal women with metastatic breast cancer. J Clin Oncol 1986;4:178-185.

33 Boccardo F, Rubagotti A, Perotta A, et al: Ovarian ablation versus goserelin with or without tamoxifen in pre-perimenopausal patients with advanced breast cancer: results of a multicentric Italian study. Ann Oncol 1994;5:337-342.

34 Taylor CW, Green S, Dalton WS, Martino S, Rector D, Ingle JN, Robert NJ, Budd GT, Paradelo JC, Natale RB, Bearden JD, Mailliard JA, Osborne CK: Multicenter randomized clinical trial of goserelin versus surgical ovariectomy in premenopausal patients with receptorpositive metastatic breast cancer: an Intergroup Study. J Clin Oncol 1998;16:994-999.

35 Klijn JGM, Blamey RW, Boccardo F, Tominaga T, Duchateau L, Sylvester R; Combined Hormone Agents Trialists' Group and the European Organization for Research and Treatment of Cancer: Combined tamoxifen and luteinizing hormone (LHRH) agonist versus LHRH agonist alone in premenopausal advanced breast cancer: a meta-analysis of four randomized trials. J Clin Oncol 2001;19:343-353.

36 Liedtke C, Thill M, Hanf V, Schütz F; AGO Breast Committee: AGO recommendations for the diagnosis and treatment of patients with advanced and metastatic breast cancer: update 2015. Breast Care 2015;10: 199-205.

37 www.ago-online.de.

38 Tutt A, Ellis P, Kilburn LS, et al: TNT: a randomized phase III trial of carboplatin (C) compared with docetaxel (D) for patients with metastatic or recurrent locally advanced triple negative or BRCA1/2 breast cancer (CRUK/07/012). Cancer Res 2015;75(suppl):S3-01.

39 Lang I, Brodowicz T, Ryvo L, Kahan Z, Greil R, Beslija S, Stemmer SM, Kaufman B, Zvirbule Z, Steger GG, Melichar B, Pienkowski T, Sirbu D, Messinger D, Zielinski C; Central European Cooperative Oncology Group: Bevacizumab plus paclitaxel versus bevacizumab plus capecitabine as first-line treatment for HER2-negative metastatic breast cancer: interim efficacy results of the randomised, open-label, non-inferiority, phase 3 TURANDOT trial. Lancet Oncol 2013; 14:125-133.

40 Miller K, Wang M, Gralow J, Dickler M, Cobleigh M, Perez EA, Shenkier T, Cella D, Davidson NE: Paclitaxel plus bevacizumab versus paclitaxel alone for metastatic breast cancer. N Engl J Med 2007;357:26662676.

41 Robert NJ, Diéras V, Glaspy J, Brufsky AM, Bondarenko I, Lipatov ON, Perez EA, Yardley DA, Chan SY, Zhou X, Phan SC, O'Shaughnessy J: RIBBON-1: randomized, double-blind, placebo-controlled, phase III trial of chemotherapy with or without bevacizumab for first-line treatment of human epidermal growth factor receptor 2-negative, locally recurrent or metastatic breast cancer. J Clin Oncol 2011;29:1252-1260.

42 Miles DW, Diéras V, Cortés J, Duenne AA, Yi J, O'Shaughnessy J: First-line bevacizumab in combination with chemotherapy for HER2-negative metastatic breast cancer: pooled and subgroup analyses of data from 2447 patients. Ann Oncol 2013;24:2773-2780.

43 www.ago-online.de.

44 Dawood S, Gonzalez-Angulo AM, Albarracin C, Yu TK, Hortobagyi GN, Buchholz TA, Woodward WA: Prognostic factors of survival in the trastuzumab era among women with breast cancer and brain metastases who receive whole brain radiotherapy: a single-institution review. Cancer 2010;116:3084-3092. 
45 Slamon DJ, Leyland-Jones B, Shak S, Fuchs H, Paton V, Bajamonde A, Fleming T, Eiermann W, Wolter J, Pegram M, Baselga J, Norton L: Use of chemotherapy plus a monoclonal antibody against HER2 for metastatic breast cancer that overexpresses HER2. N Engl J Med 2001;344:783-792.

46 Baselga J, Cortés J, Kim SB, Im SA, Hegg R, Im YH, Roman L, Pedrini JL, Pienkowski T, Knott A, Clark E, Benyunes MC, Ross G, Swain SM; CLEOPATRA Study Group l: Pertuzumab plus trastuzumab plus docetaxel for metastatic breast cancer. N Engl J Med 2012;366: 109-119.

47 Verma S, Miles D, Gianni L, Krop IE, Welslau M, Baselga J, Pegram M, Oh DY, Diéras V, Guardino E, Fang L, Lu MW, Olsen S, Blackwell K; EMILIA Study Group: Trastuzumab emtansine for HER2-positive advanced breast cancer. N Engl J Med 2012;367:17831791.

48 Geyer CE, Forster J, Lindquist D, Chan S, Romieu CG Pienkowski T, Jagiello-Gruszfeld A, Crown J, Chan A, Kaufman B, Skarlos D, Campone M, Davidson N, Berger M, Oliva C, Rubin SD, Stein S, Cameron D: Lapatinib plus capecitabine for HER2-positive advanced breast cancer. N Engl J Med 2006;355:2733-2743.

49 Johnston S, Pippen J Jr, Pivot X, Lichinitser M, Sadeghi S, Dieras V, Gomez HL, Romieu G, Manikhas A, Kennedy MJ, Press MF, Maltzman J, Florance A, O'Rourke L, Oliva C, Stein S, Pegram M: Lapatinib combined with letrozole versus letrozole and placebo as first-line therapy for postmenopausal hormone receptor-positive metastatic breast cancer. J Clin Oncol 2009;27: 5538-5546.

50 Blackwell KL, Burstein HJ, Storniolo AM, Rugo HS, Sledge G, Aktan G, Ellis C, Florance A, Vukelja S, Bischoff J, Baselga J, O’Shaughnessy J: Overall survival benefit with lapatinib in combination with trastuzumab for patients with human epidermal growth factor receptor 2-positive metastatic breast cancer: final results from the EGF104900 Study. J Clin Oncol 2012; 30:2585-2592.

51 Chan A, Delaloge S, Holmes FA, Moy B, Iwata H, Harvey VJ, Robert NJ, Silovski T, Gokmen E, Von Minckwitz G, Ejlertsen B, Chia SKL, Mansi J, Barrios CH, Gnant M, Wong A, Bryce R, Yao B, Martin M: Neratinib after adjuvant chemotherapy and trastuzumab in HER2-positive early breast cancer: primary analysis at 2 years of a phase 3 , randomized, placebo-controlled trial (ExteNET). J Clin Oncol 2015;33(suppl):abstr 508

52 Fruman DA, Rommel C: PI3K and cancer: lessons, challenges and opportunities. Nat Rev Drug Discov 2014;13:140-156.

53 Fu X, Osborne CK, Schiff R: Biology and therapeutic potential of PI3K signaling in ER+/HER2-negative breast cancer. Breast 2013;22(suppl 2):S12-18.

54 Loibl S, Majewski I, Guarneri V, Nekljudova V, McCormick Holmes E, Bria E, Denkert C, Eidtmann H, Sotiriou C, Loi S, Andre F, Untch M, Conte PF, PiccartGebhart MJ, Von Minckwitz C, Baselga J: Correlation of PIK3CA mutation with pathological complete response in primary HER2-positive breast cancer: combined analysis of 967 patients from three prospective clinical trials. J Clin Oncol 2015;33(suppl):abstr 511.
55 Slamon DJ, Hurvitz SA, Chen D, Andre F, Tseng LM, Jerusalem GHM, Wilks S, O’Regan R, Isaacs C, Toi M, Burris HA, He W, Riester M, Robinson D, Taran T, Gianni L: Predictive biomarkers of everolimus efficacy in HER2+ advanced breast cancer: combined exploratory analysis from BOLERO-1 and BOLERO-3. J Clin Oncol 2015;33(suppl):abstr 512.

56 Choi YJ, Anders L: Signaling through cyclin D-dependent kinases. Oncogene 2014;33:1890-1903.

57 Finn RS, Dering J, Conklin D, Kalous O, Cohen DJ, Desai AJ, Ginther C, Atefi M, Chen I, Fowst C, Los G, Slamon DJ: PD 0332991, a selective cyclin D kinase 4/6 inhibitor, preferentially inhibits proliferation of luminal estrogen receptor-positive human breast cancer cell lines in vitro. Breast Cancer Res 2009;11:R77.

58 Finn RS, Crown JP, Lang I, Boer K, Bondarenko IM, Kulyk SO, Ettl J, Patel R, Pinter T, Schmidt M, Shparyk Y, Thummala AR, Voytko NL, Fowst C, Huang X, Kim ST, Randolph S, Slamon DJ: The cyclin-dependent kinase $4 / 6$ inhibitor palbociclib in combination with letrozole versus letrozole alone as first-line treatment of oestrogen receptor-positive, HER2-negative, advanced breast cancer (PALOMA-1/TRIO-18): a randomised phase 2 study. Lancet Oncol 2015;16:25-35.

59 Turner NC, Ro J, André F, Loi S, Verma S, Iwata H, Harbeck N, Loibl S, Huang Bartlett C, Zhang K, Giorgetti C, Randolph S, Koehler M, Cristofanilli M: Palbociclib in hormone-receptor-positive advanced breast cancer. N Engl J Med 2015;373:209-219.

60 Patnaik A, Rosen ALS, Tolaney SM, Tolcher AW, Goldman JW, Gandhi L, Papadopoulos KP, Beeram M, Rasco DW, Myrand SP, Kulanthaivel P, Li L, Frenzel M, Cronier DM, Chan EM, Flaherty KT, Wen PY, Shapiro GI: LY2835219, a novel cell cycle inhibitor selective for CDK4/6, in combination with fulvestrant for patients with hormone receptor positive (HR+) metastatic breast cancer. J Clin Oncol 2014;32(suppl):abstr 534

61 Munster PN, Hamilton EP, Franklin C, Bhansali S, Wan K, Hewes B, Jurice D: Phase lb study of LEE011 and BYL719 in combination with letrozole in estrogen receptor-positive, HER2-negative breast cancer (ER+, HER2 - BC). J Clin Oncol 2014;32(suppl):abstr 533.

62 Nanda R, Chow LQ, Dees EC, Berger R, Gupta S, Geva R, Pusztai L, Dolled-Filhart M, Emancipator K, Gonzalez EJ, Houp J, Pathiraja K, Karantza V, Iannone R, Gause CK, Cheng JD, Buisseret L: A phase Ib study of pembrolizumab (MK-3475) in patients with advanced triple-negative breast cancer. Cancer Res 2015;75(suppl): S1-09.

63 Farmer H, McCabe N, Lord CJ, Tutt AN, Johnson DA, Richardson TB, Santarosa M, Dillon KJ, Hickson I, Knights C, Martin NM, Jackson SP, Smith GC, Ashworth A: Targeting the DNA repair defect in BRCA mutant cells as a therapeutic strategy. Nature 2005;434: 917-921.

64 Maass N, Schütz F, Fasching PA, Fehm T, Janni W, Kümmel S, Kolberg HC, Lüftner D, Wallwiener M, Lux MP: Breast cancer update 2014 - focus on the patient and the tumour. Geburtshilfe Frauenheilkd 2015; 75:170-182.
Baselga J, Campone M, Piccart M, et al: Everolimus in postmenopausal hormone-receptor-positive advanced breast cancer. N Engl J Med 2012;366:520-529.

66 Bachelot T, Bourgier C, Cropet C, Ray-Coquard I, Fer rero JM, Freyer G, Abadie-Lacourtoisie S, Eymard JC Debled M, Spaëth D, Legouffe E, Allouache D, El Kouri C, Pujade-Lauraine E: Randomized phase II trial of everolimus in combination with tamoxifen in patients with hormone receptor-positive, human epidermal growth factor receptor 2-negative metastatic breast cancer with prior exposure to aromatase inhibitors: a GINECO study. J Clin Oncol 2012;30:27182724.

67 Rugo HS, Tredan O, Ro J, Morales S, Musolino A, Afonso N, Ferreira M, Park KH, Cortes J, Tan AR, Blum JL, Eaton L, Gause CK, Wang A, Im E, Mauro DJ, Baselga J: Results from the phase 2 trial of ridaforolimus, dalotuzumab, and exemestane compared to ridaforolimus and exemestane in advanced breast cancer. Cancer Res 2015;75(suppl):PD5-1.

68 Mayer, IA, Abramson VG, Isakoff SJ, Forero A, Balko JM, Kuba MG, Sanders ME, Yap JT, Van den Abbeele AD, Li Y, Cantley LC, Winer E, Arteaga CL: Stand up to cancer phase Ib study of pan-phosphoinositide3-kinase inhibitor buparlisib with letrozole in estrogen receptor-positive/human epidermal growth factor receptor 2-negative metastatic breast cancer. J Clin Oncol 2014;32:1202-1209.

69 Ma CX, Wang J, Luo J, Naughton M, Nagaraj G, Bazzell N, Ellis MJ: A phase I study of BKM120 and fulvestrant in postmenopausal women with estrogen receptor positive metastatic breast cancer. Cancer Res 2013; 73(suppl):PD1-4.

70 Krop I, Johnston S, Mayer IA, et al: The FERGI phase II study of the PI3K inhibitor pictilisib (GDC-0941) plus fulvestrant vs fulvestrant plus placebo in patients with $\mathrm{ER+}$, aromatase inhibitor (AI)- resistant advanced or metastatic breast cancer. Cancer Res 2015: 75(suppl):S2-02.

71 Janku F, Juric D, Cortes J, Rugo H, Burris HA, Schuler M, Deschler-Baier B, Middleton MR, Gil-Martin M, Berlin J, Winer E, Bootle D, Blumenstein L, Demanse D, Coughlin C, Quadt C, Baselga J: Phase I study of the PI3Ka inhibitor BYL719 plus fulvestrant in patients with PIK3CA-altered and wild type ER+/HER2- locally advanced or metastatic breast cancer. Cancer Res 2015:75(suppl):PD5-5.

72 Shah PD, Moynahan ME, Modi S, Caravella BA, Datko FM, Zamora S, Comen E, Gilewski T, Sugarman SM D'Andrea G, Lake DE, Goldfarb SB, Patil S, Covey A, Berger MF, Lacouture ME, Norton L, Hudis CA, Baselga J, Chandarlapaty S, Dickler MN: Phase I trial: PI3Ka inhibitor BYL719 plus aromatase inhibitor (AI) for patients with hormone receptor-positive $(\mathrm{HR}+)$ metastatic breast cancer (MBC). Cancer Res 2015: 75(suppl):PD5-3. 